\title{
ANTIMICROBIAL AND TOXICOLOGICAL STUDIES OF SOME METAL COMPLEXES OF 4- METHYLPIPERAZINE-1-CARBODITHIOATE AND PHENANTHROLINE MIXED LIGANDS
}

\author{
S.B., Kalia ${ }^{1 *}$; G., Kaushal ${ }^{1}$; M., Kumar ${ }^{1}$; S.S., Cameotra ${ }^{2}$; A., Sharma ${ }^{3}$; M.L., Verma ${ }^{4}$; S.S., Kanwar ${ }^{4}$ \\ ${ }^{1}$ Department of Chemistry, Himachal Pradesh University, Shimla-171005; ${ }^{2}$ Institute of Microbial Technology, Chandigarh; \\ ${ }^{3}$ Department of Microbiology, Indira Gandhi Medical College and Hospital, Shimla; ${ }^{4}$ Department of Biotechnology, Himachal \\ Pradesh University, Shimla-171005.
}

Submitted: November 14, 2008; Returned to authors for corrections: February 11, 2009; Approved: May $15,2009$.

\begin{abstract}
A few mixed ligand transition metal carbodithioate complexes of the general formula [M(4MPipzcdt $\left.)_{\mathrm{x}}(\text { phen })_{\mathrm{y}}\right] \mathrm{Y}(\mathrm{M}=\mathrm{Mn}(\mathrm{II}), \mathrm{Co}(\mathrm{II}), \mathrm{Zn}(\mathrm{II}) ;$ 4-MPipzcdt = 4-methylpiperazine-1-carbodithioate; phen $=1,10$-phenanthroline; $\mathrm{x}=1$ and $\mathrm{y}=2$ when $\mathrm{Y}=\mathrm{Cl} ; \mathrm{x}=2$ and $\mathrm{y}=1$ when $\mathrm{Y}=$ nil) were synthesized and screened for their antimicrobial activity against Candida albicans, Escherichia coli, Pseudomonas aeruginosa, Staphylococcus aureus and Enterococcus faecalis by disk diffusion method. All the complexes exhibited prominent antimicrobial activity against tested pathogenic strains with the MIC values in the range $<8-512 \mu \mathrm{gmL}^{-1}$. The complexes $\left[\mathrm{Mn}(4-\mathrm{MPipzcdt})_{2}(\mathrm{phen})\right]$ and $[\mathrm{Co}(4-$ MPipzcdt)(phen) $)_{2} \mathrm{Cl}$ inhibited the growth of Candida albicans at a concentration as low as $8 \mu \mathrm{gmL}^{-1}$. The complexes were also evaluated for their toxicity towards human transformed rhabdomyosarcoma cells (RD cells). Moderate cell viability of the RD cells was exhibited against the metal complexes.
\end{abstract}

Key words: antimicrobial, metal ions, 4-methylpiperazine-1-carbodithioate, MIC, zone of inhibition

\section{INTRODUCTION}

1,1-Dithiolato systems involving sulfur donor ligands are of interest due to their potential biological activities and applications in the fields of rubber technology. Dithiocarbamates have long been used as agricultural fungicides, and are also tested in various medical applications. Tetraethylthiuram disulphide (TETDS) is used in the treatment of chronic alcoholism (2), inhibition of secondary effects of cis-platin, in the treatment of HIV infection (12) and heavy metal toxicity $(1,10)$. The diethyldithiocarbamate molecule (DEDTC) has also been used as inhibitor of cis-platin toxicity without inhibition of the antitumor activity. Metal dithiocarbamates are now available for medicinal or for diagnostic use as radiopharmaceuticals and for diagnostic kit (17). Number of reports on antifungal $(5,21)$, antibacterial $(4,22,24,27,28)$, antialkylation $(9,19)$, anticancer and apoptosis inducing activity (1) of the metal dithiocarbamate complexes of the mixed ligands have been currently seen in literature where free dithiocarbamate ligand has been obtained from secondary dialkylamine. The persistent use of cytotoxic drugs, corticosteroids, antibiotics and immunosuppressants has resulted in an increase in systemic opportunistic microbial infections. The problem of 
antibiotic resistance has now reached a crisis point (3) and there is a need to redouble efforts towards the design of new drugs

In view of this in vitro screening of some new transition metal complexes of 4-methylpiperazine-1-carbodithioate and nitrogen based mixed ligand phen against microbial strains, viz. Candida albicans, Escherichia coli, Pseudomonas aeruginosa, Staphylococcus aureus and Enterococcus faecalis was undertaken to study their role as microbiocidal compounds.

\section{MATERIAL AND METHODS}

\section{Chemicals}

1-Methylpiperazine, calcium chloride, carbon disulphide and dimethyl sulphoxide (s.d. fine chemicals, Mumbai); carbon tetrachloride and 1,10-phenanthroline (Merck); Dulbecco's Modified Eagles Medium (DMEM, Sigma Chemical Co., USA); fetal calf serum (FCS); Mueller Hinton agar, EDTA and trypsin 1:250 (Himedia Chemicals, Mumbai), nystatin (BDH) and chloramphenicol were obtained from commercial suppliers. All the chemicals were of high purity.

\section{Synthesis of the ligands}

The ligands 4-methylpiperazine-1-carbodithioic acid (4MPipzcdtH) and sodium-4-methylpiperazine-1carbodithioate monohydrate (4-MPipzcdtNa. $\mathrm{H}_{2} \mathrm{O}$ ) were prepared by the method as reported earlier $(13,16)$.

\section{Synthesis of mixed ligand transition metal carbodithioate complexes}

[M(4-MPipzcdt) $\left.)_{x}(\text { phen })_{y}\right] Y(M=M n(I I), C o(I I), Z n(I I) ; x=1$, $y=2$ when $Y=C l$ and $x=2, y=1$ when $Y=$ nil):

Aqueous solution of $0.566 \mathrm{mmol}$ of $\mathrm{MCl}_{2} \cdot \mathrm{xH}_{2} \mathrm{O}$ was added with stirring to an aqueous solution of $1.698 \mathrm{mmol}$ of nitrogenous base, phen. To the resulting coloured solution of the $\left[\mathrm{M}(\text { phen })_{3}\right] \mathrm{Cl}_{2}$ complex was added with stirring an aqueous solution $(0.565 \mathrm{mmol}$ when $\mathrm{x}=1, \mathrm{y}=2, \mathrm{Y}=\mathrm{Cl}$ and
1.13 mmol when $\mathrm{x}=2, \mathrm{y}=1, \mathrm{Y}=$ nil) of 4-MPipzcdtNa. $\mathrm{H}_{2} \mathrm{O}$. The reaction mixture was stirred at $30{ }^{\circ} \mathrm{C}$ for another two hours to form precipitated complex. Orange coloured precipitates for manganese, dark green for cobalt and white for zinc mixed ligand complexes were obtained. The precipitates were filtered, washed with water and dried in air. Final drying of the product was done over calcium chloride in a desiccator. The phenanthroline complexes of cobalt (II) were obtained in the solution state and were extracted in $\mathrm{CCl}_{4}$ so as to separate the pure complex from the byproducts phen and $\mathrm{NaCl}$. $\mathrm{CCl}_{4}$ was completely evaporated to obtain the complex in a solid form.

\section{Mmicrobial strains}

C. albicans, E. coli NCTC 10418, P. aeruginosa NCTC 10662, S. aureus NCTC 6571 and E. faecalis ATCC 29212 were obtained from Department of Microbiology, Indira Gandhi Medical College, Shimla, India. All these strains were subcultured regularly on the appropriate media.

\section{Human cell line}

$\mathrm{RD}$ cells (a transformed human rhabdomyosarcoma cell line) obtained from Central Research Institute, Kasauli, India were maintained in DMEM supplemented with $10 \%$ FCS and $40 \mathrm{gml}^{-1}$ of gentamicin. The confluent monolayers culture developed in $25 \mathrm{~cm}^{2}$-canted neck flasks were trypsinized to obtain single-cell suspension. The cells were suspended in DMEM $(18 \mathrm{ml})$ and this homogeneous suspension $(1.5 \mathrm{ml})$ was added to each of the wells of a sterile 12 wells tissue culture plate (Tarson, Mumbai, India). The cells attained confluency in 5-6 days when they were used for performing cytotoxic studies with mixed ligand complexes of 4methylpiperazine-1-carbodithiaote and phen.

\section{In vitro anti-microbial screening}

\section{Disk Diffusion Method: (Adaptation of Kirby-Bauer Test} according to CLSI) (26)

All methodology and steps were followed according to CLSI except for disc content. Concentration of disc content was roughly estimated by comparing their MIC (break point) 
values to that of known antibiotics. An inoculum of $0.5 \mathrm{Mc}$ Farland standard $\left(10^{8} \mathrm{cfu} / \mathrm{ml}\right)$ was applied on Mueller Hinton agar (a depth of $4 \mathrm{~mm}$ in a petridish of $100 \mathrm{~mm}$ diameter). Maximum 6 discs were applied on each plate and they were incubated at $35{ }^{\circ} \mathrm{C}$ for $16-18$ hours. Zone of inhibition was measured including the disc diameter $(6 \mathrm{~mm})$.

\section{Agar dilution method}

Antimicrobial studies against the selected strains were performed by determining MIC (mimimum inhibitory concentration)/break point value by agar dilution method $(6,14)$. The results were compared with that of chloramphenicol $\left(\mathrm{MIC}=4 \mu \mathrm{gmL}^{-1}\right) \quad(7)$, a standard broadspectrum antibiotic for bacterial strains and nystatin (4-8 $\mu \mathrm{gmL}^{-1}$ ) (11) for Candida albicans as positive control. The stock of each of the synthetic drug was prepared in DMSO.

\section{Cytotoxic assay of mixed ligand complexes}

To each of the wells of 24-wells tissue culture plate, an appropriate volume of mixed ligand complexes to give the desired concentration of the test compound was added in triplicate. The complexes were tested at an increasing concentration to study the effect of higher concentrations on the RD cells. In each of the assays, appropriate controls (in triplicate) without complexes (negative control) were also included. The treated or control cells were incubated for $48 \mathrm{~h}$ at $37^{\circ} \mathrm{C}$ in a $\mathrm{CO}_{2}$ incubator when the cells were morphologically examined and then used to perform dye binding cytotoxic assay (15).

The DMEM from each of the wells was completely removed with an auto-pipette; the free floating and or loosely bound cells were washed off with two washings with sterile PBS (pH 7.2) followed by fixation in $20 \%$ methanol (1 $\mathrm{ml} /$ well). The fixed cells were washed once in PBS followed by exposure to crystal violet prepared in acetic acid $(0.1 \%$ $\mathrm{w} / \mathrm{v} ; 1 \mathrm{ml} / \mathrm{well}$ ) for 30 minutes at room temperature. The cells fixed to the surface of wells were stained blue with crystal violet. The excess dye was washed off with washing of cells with $30 \%(\mathrm{v} / \mathrm{v})$ glacial acetic acid. Thereafter, $2.5 \mathrm{ml}$ of $30 \%$ (v/v) of glacial acetic acid was added to each of the wells.
The dye released in the acidic solution after 10 minutes was recorded at $\mathrm{A}_{450}$. The percent cell-death (cytotoxicity) was determined in relation to the controls.

\section{RESULTS AND DISCUSSION}

Antimicrobial activity of the complexes was explored by determining zone of inhibition (Disk Diffusion Tests) using nystatin/chloramphenicol as reference standard (Table 1). The observed order of zone of inhibition was $C$. albicans $>S$. aureus $>$ E. coli $>$ E. faecalis $>P$. aeruginosa.

The free ligand 4-MPipzcdtNa. $\mathrm{H}_{2} \mathrm{O}$, the base- phen and their mixed ligand complexes (when carbodithioate and nitrogenous base both are simultaneously bound to the central metal ion) showed variable in vitro antimicrobial activities against test strains (Table 2). The ligands phen and 4MPipzcdtH showed the lowest MIC values of 32 and 128 $\mu \mathrm{gmL}^{-1}$ against $C$. albicans and $S$. aureus, respectively.

All the tested complexes were found to be highly effective against $C$. albicans with the MIC values in the range <8-64 $\mathrm{MgmL}^{-1}$ (Table 2). The complex [Co(4MPipzcdt)(phen $\left.)_{2}\right] \mathrm{Cl}$ inhibited the growth of the pathogen at a concentration lower than $8 \mu \mathrm{gmL}^{-1}$ while the complex $\left[\mathrm{Mn}(4-\mathrm{MPipzcdt})_{2}\right.$ (phen)] inhibited its growth at $8 \mu \mathrm{gmL}^{-1}$ (Table 2), low enough not to cause undesirable damage to the host. To the best of our knowledge the MIC values data of our mixed ligand metal complexes when compared with the literature data (24), against $C$. albicans, were highly encouraging The newly synthesized complexes were highly inhibitory for $E$. coli with the MIC values in the range 16-256 $\mu \mathrm{gmL}^{-1}$ (Table 2). The complex [Co(4-MPipzcdt)(phen) $\left.)_{2}\right] \mathrm{Cl}$ possessed the most potent antimicrobial activity at $16 \mu \mathrm{gmL}^{-}$

${ }^{1}$. The complexes $\left[\mathrm{M}(4-\mathrm{MPipzcdt})_{2}(\right.$ phen $\left.)\right](\mathrm{M}=\mathrm{Mn}(\mathrm{II})$ and $\mathrm{Co}(\mathrm{II})$ ) were also found to be remarkably active against $E$. coli with MIC value of $32 \mu \mathrm{gmL}^{-1}$. The MIC value of 64 $\mu \mathrm{gmL}^{-1}$ for the complex [Mn(4-MPipzcdt)(phen) $\left.)_{2}\right] \mathrm{Cl}$ was also satisfactory. Comparison of the MIC values of the mixed ligand complexes of the present study with those of the similar complexes reported in the literature (23) indicated 
that the cobalt complex, $\left[\mathrm{Co}(4-\mathrm{MPipzcdt})(\text { phen })_{2}\right] \mathrm{Cl}$

appeared to a promise a best antimicrobial agent.

The mixed ligand complexes in the present study also showed antibacterial activities against $P$. aeruginosa with the MIC values in the range of $16-512 \mu \mathrm{gmL}^{-1}$ (Table 2). The complex $\left[\mathrm{Co}(4-\mathrm{MPipzcdt})(\mathrm{phen})_{2}\right] \mathrm{Cl}$ was found to be the most effective agent against $P$. aeruginosa at $16 \mu \mathrm{gmL}^{-1}$ whereas $\left[\mathrm{Co}(4-\mathrm{MPipzcdt})_{2}(\right.$ phen $\left.)\right]$ complex inhibited the bacterial growth at a concentration of $32 \mu \mathrm{gmL}^{-1}$. The grampositive pathogenic strain of $S$. aureus resisted for its growth with MIC values in the range $64-256 \mu \mathrm{gmL}^{-1}$ (Table 2). The complexes $\left[\mathrm{Mn}(4-\mathrm{MPipzcdt})(\mathrm{phen})_{2}\right] \mathrm{Cl}$ and $[\mathrm{Mn}(4-$ MPipzcdt $)_{2}($ phen)] screened also exhibited effective antimicrobial activities against $S$. aureus at $64 \mu \mathrm{gmL}^{-1}$ (Table 2). All the complexes possessed antimicrobial activities against $E$. faecalis and have been found to be active in the range 128-256 $\mathrm{gmL}^{-1}$ (Table 2). The complexes [M(4MPipzcdt $)_{2}($ phen $\left.)\right](\mathrm{M}=\mathrm{Mn}(\mathrm{II}), \mathrm{Co}(\mathrm{II})$ and $\mathrm{Zn}(\mathrm{II}))$ and $\left[\mathrm{Co}(4-\mathrm{MPipzcdt})(\text { phen })_{2}\right] \mathrm{Cl}$ were also markedly effective against $E$. faecalis at MIC value of $128 \mu \mathrm{gmL}^{-1}$.

Table 1. Antimicrobial activity (Zone of Inhibition) of the compounds

\begin{tabular}{lccccc}
\hline Test Compound & C. albicans & E. coli & P. aeruginosa & S. aureus & E. faecalis \\
\hline$\left.[\text { Mn(4-MPipzcdt)(phen })_{2}\right] \mathrm{Cl}$ & 36 & 14 & 6 & 19 & 12 \\
{$\left[\mathrm{Co}(4-\mathrm{MPipzcdt})(\mathrm{phen})_{2}\right] \mathrm{Cl}$} & 39 & 19 & 6 & 15 & 8 \\
{$\left[\mathrm{Zn}(4-\mathrm{MPipzcdt})(\mathrm{phen})_{2}\right] \mathrm{Cl}$} & 30 & 6 & 6 & 7 & 7 \\
{$\left[\mathrm{Mn}(4-\mathrm{MPipzcdt})_{2}\right.$ (phen) $]$} & 35 & 17 & 6 & 16 & 12 \\
{$\left[\mathrm{Co}(4-\mathrm{MPipzcdt})_{2}(\right.$ phen $\left.)\right]$} & 18 & 7 & 6 & 8 & 6 \\
{$\left[\mathrm{Zn}(4-M P i p z c d t)_{2}(\right.$ phen $\left.)\right]$} & 33 & 12 & 6 & 18 & 8 \\
Chloramphenicol & - & 16 & 18 & 20 & 10 \\
Nystatin & 36 & - & - & - & - \\
\hline
\end{tabular}

Values are zone of inhibition [mm, including the diameter of the disk $(6 \mathrm{~mm})$ ]

Table 2. Antimicrobial activity of the compounds

Test compound

Minimum Inhibitory Concentration $\left(\mu \mathrm{gml}^{-1}\right)$

\begin{tabular}{|c|c|c|c|c|c|}
\hline & C. albicans & E. coli & P. aeruginosa & S. aureus & E. faecalis \\
\hline$\left[\mathrm{Mn}(4-\mathrm{MPipzcdt})(\text { phen })_{2}\right] \mathrm{Cl}$ & 16 & 64 & 256 & 64 & 256 \\
\hline$\left[\mathrm{Co}(4-\mathrm{MPipzcdt})(\mathrm{phen})_{2}\right] \mathrm{Cl}$ & 8 & 16 & 16 & 128 & 128 \\
\hline$\left[\mathrm{Zn}(4-\mathrm{MPipzcdt})(\mathrm{phen})_{2}\right] \mathrm{Cl}$ & 64 & 256 & 128 & 128 & 256 \\
\hline$\left[\mathrm{Mn}(4-\mathrm{MPipzcdt})_{2}(\right.$ phen $\left.)\right]$ & 8 & 32 & 512 & 64 & 128 \\
\hline$\left[\mathrm{Co}(4-\mathrm{MPipzcdt})_{2}(\right.$ phen $\left.)\right]$ & 16 & 32 & 32 & 256 & 128 \\
\hline$\left[\mathrm{Zn}(4-\mathrm{MPipzcdt})_{2}(\mathrm{phen})\right]$ & 16 & 128 & 256 & 256 & 128 \\
\hline 1-MPipz & 512 & 1024 & 1024 & 512 & 1024 \\
\hline 4-MPipzcdtH & 128 & 1024 & 1024 & 128 & 1024 \\
\hline Phen & 32 & 32 & 256 & 32 & 128 \\
\hline
\end{tabular}


At a concentration of $25 \mu \mathrm{gmL}^{-1}$ all the mixed-ligand complexes were well tolerated by the RD cells. (Table 3). The complex $\left[\mathrm{Co}(4-\mathrm{MPipzcdt})(\mathrm{phen})_{2}\right] \mathrm{Cl}$ exhibiting the best antimicrobial activity (least MIC $<8 \quad \mu \mathrm{gmL}^{-1}$ ) showed negligible toxicity towards the RD cells at a concentration 25 $\mu \mathrm{gmL}^{-1}$.

The discordance in the observed MIC/break point data and disc diffusion test data may most plausibly be attributed to the diffusion properties in the Mueller Hinton agar and the concentrations of the compounds under study.

Table 3. Effect of mixed-ligand metal carbodithioate complexes on the RD cells.

Test compound

Cell survival (\%) at the selected test compound concentration

Control $25 \mu \mathrm{gmL}^{-1} \quad 50 \mu \mathrm{gmL}^{-1} \quad 75 \mu \mathrm{gmL}^{-1}$

\begin{tabular}{lcccc}
\hline$\left[\mathrm{Mn}(4-M P i p z c d t)(\text { phen })_{2}\right] \mathrm{Cl}$ & 100 & 75.4 & 73.5 & 45.4 \\
{$\left[\mathrm{Co}(4-M P i p z c d t)(\text { phen })_{2}\right] \mathrm{Cl}$} & 100 & 90.8 & 85.3 & 60.2 \\
{$\left[\mathrm{Zn}(4-\mathrm{MPipzcdt})(\text { phen })_{2}\right] \mathrm{Cl}$} & 100 & 87 & 64.3 & 58.2 \\
{$\left[\mathrm{Mn}(4-\mathrm{MPipzcdt})_{2}(\right.$ phen $\left.)\right]$} & 100 & 63 & 45 & 39 \\
{$\left[\mathrm{Co}(4-\mathrm{MPipzcdt})_{2}(\right.$ phen $\left.)\right]$} & 100 & 70 & 58 & 45 \\
{$\left[\mathrm{Zn}(4-\mathrm{MPipzcdt})_{2}\right.$ (phen) $]$} & 100 & 61 & 59 & 55 \\
\hline
\end{tabular}

The high antimicrobial activities of all the metal complexes surmounting that of ligands, viz. 1-MPipz, 4MPipzcdtH and phen showed that complexation of the organic ligands to the metal ions substantially enhanced their activities. Such increased activity of metal chelates has been explained by Overtone's concept (8) and the Tweedy's theory (25), according to which chelation reduces the polarity of the ligand due to partial sharing of its negative charge with the metal, favouring transportation of the complexes across the lipid layer of the cell membrane.

The dithiocarbamates were chosen for biological screening keeping in mind the presence of free hydrogen at the nitrogen atom of carbodithioate ligand and the presence of heavy metal ions coordinated to the $\mathrm{CS}_{2}$ moiety. The presence of free hydrogen at nitrogen atom can help in splitting $\mathrm{HS}^{-}$ions and the formation of isothiocyanate group (18).

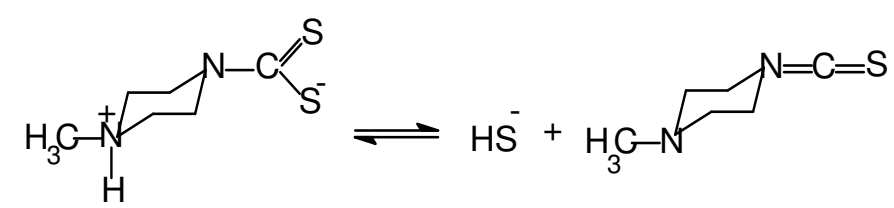

This equilibrium is forced to the right especially in the presence of heavy metals because of the formation of insoluble metal sulfides. It has been reported that isothiocyanate group has good antifungal activity. It is interesting that no free dithiocarbamic acid has been reported in literature whereas the free 4-methylpiperazine-1carbodithioic acid has been found to be very stable. Heavy metals are very reactive with proteins, particularly at the protein's sulfhydryl groups (-SH) which are free and unreduced in some of the bacterial enzymes, and they are believed to bind protein molecules together by forming bridges between the groups.

$$
\mathrm{R}-\mathrm{SH}+\mathrm{HS}-\mathrm{R} \stackrel{-2 \mathrm{H}}{\longrightarrow} \mathrm{R}-\mathrm{S}-\mathrm{S}-\mathrm{R}
$$

Because many of the proteins involved are enzymes, the cellular metabolism is disrupted and the microorganism dies. The presence of chloride ion in complexes may also result in enhanced antimicrobial activity due to the formation of hypochlorous acid when free chloride upon oxidation resulting into chlorine that reacts with water to yield 
hypochlorous acid (20). The hypochlorous acid formed, further decomposes forming hydrochloric acid and oxygen. The later, a strong oxidizing agent, destroys microbes by oxidizing cellular components (20). Antimicrobial action of chlorine compounds is also due to the combination of chlorine with proteins and enzymes of membranes.

\section{CONCLUSIONS}

The results of the study are highly encouraging because all the mixed ligand complexes exhibited prominent antimicrobial activity against tested strains with the MIC/break point values in the range $<8-512 \mu \mathrm{gmL}^{-1}$. To the best of our knowledge for the complexes $[\operatorname{Co}(4-$ MPipzcdt)(phen $\left.)_{2}\right] \mathrm{Cl}$ and $\left[\mathrm{Mn}(4-\mathrm{MPipzcdt})_{2}(\right.$ phen $\left.)\right]$ the MIC/break point value $\left(<8 \mu \mathrm{gmL}^{-1}\right)$, when compared with the literature (24) appeared to promise the best antimicrobial agent against $C$. albicans.

\section{REFERENCES}

1. Borch, R.F.; Bodenner, D.L.; Katz, J.C. (1984). Platinum Coordination Complexes in Cancer Chemotherapy, Martinus Nijhoff, Boston 154164.

2. Brewer, C. (1993). Long-term, high dose disulfiram in the treatment of alcohol abuse. Br J Psychiatry 163, 687-689.

3. Bentley, P.H.; O'Hanlon, P.J. (1997). Anti-infectives - Recent Advances in Chemistry and Structure-Activity Relationships, The Royal Society of Chemistry.

4. Baikenova, G.G.; Abdulina, G.A.; Gazaliev, A.M. (2004). Syntheis and antimicrobial activity of the Dithiocarbamates of Anabasine, Piperidine and Morpholine dithiocarbamates. Pharmaceutical Chemistry Journal 38(1), 19-20

5. Chauhan, H.P.S.; Shaik, N.M. (2005). Synthetic, spectral, thermal and antimicrobial studies on some mixed 1,3-dithia-2-stannacyclopentane derivatives with dialkyldithiocarbamates. J Inorg Biochem. 99(2), 538545.

6. Collee, J.G.; Duguid, J.P.; Fraser, A.G.; Marmion, B.P.; Mackie, M. (1996). Practical Medical Microbiology, 14 ${ }^{\text {th }}$ Ed., Vol.2, (Churchill \& Livingstone, Edinberg). 159-165.

7. Dutta, G.N.; Gogoi, J.; Buragohain, J. (2001). Inactivation of choramphenicol by Staphylococcus aureus biotype C from humans and animals. Indian J Med Res. 113, 11-13.
8. Dharamraj, N.; Viswanathamurthi, P.; Natrajan, K. (2001). Ruthenium (II) complexes containing bidentate Schiff bases and their antifungal activity. Trans Met Chem. 26, 105-109.

9. Gringeri, A.; Keng, P.C.; Borch, R.F. (1988). Diethyldithiocarbamate inhibition of murine bone marrow toxicity caused by cisdiamminedichloroplatinum(II) or diammine-(1,1cyclobutanedicarboxylato)platinum(II) Cancer Res. 48, 5708-5712.

10. Gessner, P.K.; Gessner, T. (1992). Disulfiram and its metabolite Diethyldithiocarbamate. Pharmacology and status in the treatment of alcoholism, HIV infections, AIDS and heavy metal toxicity. London, United Kingdom, Chapman and Hall.

11. Gunderson, S.M.; Hoffman, H.; Ernst, E.J. (2000). In Vitro pharmacodynamic characteristics of nystatin including time-kill and postantifungal effect. Antimicrob Agents Chemother 44(10), 28872890.

12. Hersh, E.M.; Brewton, G.; Abrams, D. (1991). Sodium (diethyldithiocarbamate) therapy in patients with symptomatic HIV infection and AIDS. A randomized, double-blind, placebo-controlled, multicenter study. Am Med Assoc 265, 1538-1544.

13. Kalia, S.B.; Kaushal, G.; Sharma, D.K. (2005). Studies on some new type of transition metal 4-methylpiperazine-1-carbodithioate complexes. Synth React Inorg Met-Org Nano-Met Chem. 35, 181-188.

14. Kalia, S.B.; Sharma, V.; Lumba, K.; Kaushal, G. Sharma, A. (2007). Antimicrobial screening of some newly synthesized transition metal complexes of a dithiocarbazate derived from isoniazid. Ind J Pharm Sci $69,438-441$.

15. Kanwar, S.S.; Lumba, K.; Gupta, S.K.; Katoch, V.M.; Singh, P.; Mishra, A.K.; Kalia, S.B. (2008). Synthesis and in vitro studies of metal complexes of isonicotinoyldithiocarbazic acid. Biotechnol Lett. 30, 677-680.

16. Manhas, B.S.; Bala, S. (1988). Infrared spectral, variable temperature magnetic susceptibility and mössbauer spectral investigations on tris(carbodithioato) iron(III) complexes. Polyhedron 7(24), 2465-2471.

17. Mauclaire, L.B. (2000). Preparation of bis-dtcs for chelating a metal for medicinal or diagnostic use such as radiopharmaceuticals and for diagnostic kit. Eric FR Appl. 15416:57.

18. Nene, Y.L.; Thapliyal, P.N. (1971). Fingicides in Plant Disease Control, $2^{\text {nd }}$ Ed. 227.

19. Pannacciulli, I.M.; Lerza, R.A.; Bogliolo, G.U.; Mencoboni, M.P. (1989). Effect of diethyldithiocarbamate on toxicity of doxorubicin, cyclophospamine and sis-diammine chloroplatinum(II). Br J Cancer. 59, 371.

20. Prescott, L.M.; Harley, J.P.; Klein, D.A. (1993). 'Microbiology', Wm C Brown Communications, Inc.

21. Sharma, R.N.; Kumar, A.; Kumari, A.; Singh, H.R.; Kumar, R. (2003). Synthesis, characterization and antifungal studies of some As (III), $\mathrm{Sb}$ (III) and $\mathrm{Bi}(\mathrm{III})$ complexes with o-tolyl ammonium dithiocarbamate. Asian J Chem . 15, 57-61. 
Kalia, S.B. et al.

22. Sharma, R.; Kaushik, N.K. (2004). Studies on organomercury(II) complexes with piperidine and 2-aminopyridine dithiocarbamates. $I J$ Chem. 43A, 769-772.

23. Singh, A.K.; Puri, B.K.; Rawlley, R.K. (1988). Indian J. Chem. 27A, 430-433.

24. Sovilz, S.P.; Avramović, N.; Katsaros, N. (2004). Syntheses and properties of mixed dinuclear copper (II) complexes with heterocyclic dithiocarbamates and a cyclic octadentate tertiary amine. Transition Metal Chem. 29, 737-742.

25. Tweedy, B.G. (1964). Phytopathology 55: 910-917.

26. WHO, Geneva (Sept. 1997). Manual on antimicrobial resistance and susceptibility testing. Diversion of emerging and other communicable diseases surveillance and control. WHO antimicrobial resistance monitoring programme.

27. Yilmaz, V.T.; Yazicilar, T.K.; Cesur, H.; Ozkanca, R.; Maras, F.Z. (2003). Metal complexes of phenylpiperazine-based dithioacarbamate ligands. Synthesis, characterization, spectroscopic, thermal and antimicrobial activity studies. Synth React Inorg Met-Org Chem. 33, 589-605.

28. Zeng, M.H.; Liang, H.; Hu, R.X. et al (2001). She-Qun. Ying Jong Huaxue, 18(10), 839 